\title{
Constructs and concepts comprising the stigma of mental illness
}

\author{
Patrick J. Michaels ${ }^{1 *}$, Marcelino López ${ }^{2}$, Nicolas Rüsch ${ }^{3}$ and Patrick W. Corrigan ${ }^{1}$
}

${ }^{1}$ Illinois Institute of Technology ${ }^{2}$ Fundación Pública Andaluza para la Integración

Social de Personas con Enfermedad Mental ${ }^{3}$ Psychiatric University Hospital in Zürich, Switzerland (Received September 16, 2012; Accepted October 18, 2012)

\begin{abstract}
People with mental illness frequently confront public stigma and may experience self-stigma. This review discusses the concepts of mental illness stigma and its consequences for those with mental illness. After a conceptual overview of stigma prominent consequences pertaining to public stigma (i.e., employment, health care quality) and self-stigma (i.e., self-confidence, quality of life, "why try" effect) are reviewed. We discuss the three main public stigma change strategies - protest, education, and contact - as well as current selfstigma change strategies (e.g., psychoeducation, cognitive-behavioral therapy). We conclude by noting that anti-stigma initiatives with more tailored content for specific groups (e.g., police officers vs. general public) may diminish the negative consequences of mental illness stigma by providing more concrete ways to help stigmatized people.
\end{abstract}

Keywords: stigma, self-stigma, mental health.

\section{Constructos y conceptos abarcativos del estigma sobre la enfermedad mental}

RESUMEN: Las personas con enfermedades mentales con frecuencia se enfrentan al estigma público y pueden experimentar autoestigma. Esta revisión analiza los conceptos referidos al estigma de las enfermedades mentales y sus consecuencias para las personas que las padecen. Después de una visión global de carácter conceptual sobre el estigma, se examinan las consecuencias más importantes del estigma público (por ejemplo empleo y calidad de la atención) y del auto-estigma (por ejemplo auto confianza, calidad de vida o el efecto "por qué intentarlo"). Se discuten también las tres principales estrategias de cambio del estigma público - protesta, educación y contacto - así como las estrategias actuales de intervención sobre el auto-estigma (por ejemplo, psicoeducación y terapia cognitiva-conductual). Concluimos señalando que iniciativas anti-estigma con contenidos específicamente adaptados para grupos específicos (por ejemplo, agentes de policía frente al público en general) pueden disminuir las consecuencias negativas del estigma de la enfermedad mental proporcionando vías más concretas para ayudar a las personas estigmatizadas.

Palabras clave: estigma, autoestigma, salud mental. 


\section{CONSTRUCTS AND CONCEPTS COMPRISING THE STIGMA OF MENTAL ILLNESS}

The stigma of mental illness is a worldwide concern that adversely impacts the life opportunities and quality of life of people with mental illness. Negative opinions and behavioral responses toward people with mental illness have been documented in Africa (Adewuya \& Makanjuola, 2005), Asia (Lauber \& Rössler, 2007), Australia (Jorm \& Wright, 2005), Europe (Mehta, Kassam, Lesse, Butler, \& Thornicroft, 2009; Schomerus, Matschinger, Kenzin, Breier, \& Angermeyer, 2006), South America (de Toledo Piza, Peluso, \& Blay, 2004), and the United States (Anglin, Link, \& Phelan, 2006; Pescosolido et al., 2010). The general public's negative beliefs and behaviors are known as public stigma, a two-pronged problem for people with mental illness. First, persons with mental illnesses must cope with symptoms, such as hallucinations, delusions, anxiety, and/or mood swings. These symptoms can make it challenging to work, live independently or maintain a desirable quality of life. Secondly, societal misunderstandings of mental disorders lead to the social exclusion of people with mental illness. While some people successfully manage their mental illness well enough to work, others have significant difficulties finding employment because employers discriminate against them (Brohan et al., 2012). Hence, mental illness results in difficulties arising from both symptomology and social disadvantages. To complicate the problem of stigma, people with mental illness may agree with societal prejudices about mental illness (e.g., that people with mental illnesses are incompetent), internalize these beliefs, and lose self-confidence.

This paper's goal is to provide a conceptual background of public and self-stigma, discuss implications of mental illness stigma for the lives of people with psychiatric conditions, and review public and self-stigma reduction strategies.

\section{WHAT IS STIGMA?}

In ancient Greek and Roman societies, the word stigma described marks that were tattooed or burned into the flesh of criminals or slaves, a visible testament to their marginal social status or deviance (Jones, 1987). In medieval Europe, marks conveying stigma included clipped ears that warned the general public to maintain their distance (Marx, 2001). By the $18^{\text {th }}$ century, stigma extended to signs of disease or physical degeneration. In the $20^{\text {th }}$ century, sociological theory had implicated both physical and symbolic markers of social deviance or disapproval. Goffman (1963), for example,explainedstigma's social existence by making the distinction between two types of prominent markings (i.e., obvious and invisible) either of which could denigrate a person's perceived social worth. The aforementioned physical markings used in Roman, Greek, and Medieval times signaled to other people alower social value while physical disabilities (e.g., congenital deformities, wheel chair use)were similarly interpreted. The second type or mark is invisible yet these too are socially denigrating to the person if known. 
Invisible stigmatized conditions can include medical diagnoses (e.g., cancer), sexual orientation, or psychiatric disabilities (e.g., schizophrenia). The critical distinction between obvious and invisible stigmatizing marks is that without verbal acknowledgment of a diagnosis, a person can continue to protect their identity (Wahl, 1999). Hiding one's mental health condition has been empirically linked to self-stigma (Corrigan \& Rao, 2012) and has been shown to be a significant life stressor (Rüsch et al., 2009a).

For people with mental illness, contemporary definitions of stigma do not signify inherent moral flaws of particular individuals or groups. Instead stigma is a socio-cultural process by which members of marginalized groups are labeled by other people as abnormal, shameful, or otherwise undesirable. This distinction definesstigma as a problem that does not reside within marked individuals, but rather stems from the stigmatizing community that has labeled people with mental illness as damaged.

\section{PUBLIC AND SELF-STIGMA}

The origin of mental illness stigma is that members of the general public make assumptions about a person based upon their psychiatric diagnosis. Such beliefs held by the general population have been referred to as public stigma. Whereas, self-stigma is a process of internalizing public stigma and simultaneously agreeing with the negative and denigrating portrayals of people with psychiatric illnesses, which are accepted as accurate representations of themselves and others with psychiatric diagnoses. Yet not all people with a mental illness self-stigmatize. Rather a person with a mental illness is confronted with three options (which the person may not be consciously aware of): to accept public stigma as valid, reject it, or ignore it. To explain the connection between public and self-stigma, the social-cognitive model of mental illness stigma is explained and delineated into stereotypes, prejudice, and discrimination.

From a public stigma standpoint, stereotypes are defined as negative expectations about a person with a mental illness (e.g., a person with a mental illness is incompetent and dangerous). Prejudice is defined as both agreeing with a stereotype and consequently experiencing negative affective feelings about the person with a mental illness (e.g., feeling afraid of persons with a mental illness because they believe that they are dangerous). Prejudice may lead to discrimination such as with holding opportunities (e.g., work or housing) from the person with a mental illness based solely on their diagnosis.

Self-stigma is also broken down into stereotypes, prejudice, and discrimination; however, the notable difference is the identified person. This means that persons with a psychiatric diagnosis apply the public's perceptions of a mental illness to themselves. From this self-stigma perspective, stereotypes are defined as negative public beliefs about people with mental illness subsequently interpreted as accurate prototypical portrayals. For example, a self-stigma stereotype is when a person with a psychiatric diagnosis concurs that all people with mental 
illnesses are unintelligent and/or dangerous. Prejudice results from agreement with self-stigma stereotypes and/or experiencing negative feelings about oneself because of having a mental illness (e.g., a person with a mental illness believes they are unintelligent and experiences shame, low self-confidence and/or diminished self-esteem). Prejudicial beliefs may then lead to self-stigma-related discrimination (e.g., avoiding treatment or not allowing oneself needed work accommodations). These adverse consequences of self-stigma may be conceived of in terms of the "why try" effect, in which internalized stereotypes and prejudice lead the person to give up on their personal goals (Corrigan, Larson \& Rüsch, 2009). Diminished hope, confidence, self-esteem and negative attributions, for example, might decrease an individual's perceived competence in multiple domains, ultimately leading to withdrawal and the foreclosure of important educational, social and career goals. For example, a student with significant psychiatric disabilities may have internalized the view of individuals with such disabilities as incompetent or incapable of achieving the required performance level relative to students without disabilities therefore feeling little hope in their own future success. "It would be pointless for someone like me to go to business school," they might conclude, "so why even try?" Empirical studies support this view: people with mental illness who devalued the life domains of work and education showed higher levels of hopelessness and more social withdrawal (Rüsch et al., 2009b).

Table 1.The Components of Public and Self-Stigma

\begin{tabular}{|l|l|}
\hline Public Stigma & Self-Stigma \\
\hline $\begin{array}{l}\text { Stereotype: } \\
\text { Negative belief about a group } \\
\text { such as: }\end{array}$ & $\begin{array}{l}\text { Stereotype: } \\
\text { Negative belief about the } \\
\text { Incompetence }\end{array}$ \\
$\begin{array}{l}\text { Character weakness } \\
\text { Dangerousness }\end{array}$ & Chcompetence \\
Prejudice: & Dangerousness \\
Agreement with belief and/or & Prejudice: \\
Negative emotional reactions & Agreement with belief and/or \\
may include: & Negative emotional \\
Anger & reactions may include: \\
Fear & Low self-esteem or \\
& Low self-efficacy \\
Discrimination: & Discrimination: \\
Behavior response to prejudice & Behavior response to \\
such as: & prejudice such as: \\
Refuse work and housing & Failure to pursue work \\
opportunities & and housing \\
Withhold help & opportunities \\
& Does not seek help \\
& \\
\hline
\end{tabular}




\section{CONSEQUENCES OF STIGMA}

The stigma of mental illness has been noted to significantly limit many life opportunities for people with mental illness. In particular, the general public's prejudicial and discriminatory behaviors and practices stemming from these stigmatizing beliefs and attitudes exclude people with mental illnesses from obtaining work (Cechnicki, Angermeyer, \& Bielańska, 2011; Sharac, McCrone, Clement, \& Thornicroft, 2010) and housing (Link \& Phelan, 2001; Wahl, 1999). In particular, public stigma negatively impacts employers' willingness to hire and accommodate people with mental illness in their organizations. Yet work is critical to one's financial self-sufficiency thereby supporting one's family, educational pursuits, and hobbies. A cross-cultural study of employers' attitudes demonstrated that people with mental illness are among the last to be considered for employment (Corrigan, Tsang, Shi, Lam, \& Larson, 2010). Unfortunately this message has been rather clearly communicated to people with mental illness who expect employers to discriminate against them (Brohan et al., 2012; Cechnicki, Angermeyer, \& Bielańska, 2011). Even laws prohibiting discrimination and requiring accommodations from employers often do not lead to increased work opportunities because employers'beliefs remain a significant obstacle to providing employment (Bambra \& Pope, 2007; Scheid, 2005). Given such negative beliefs, it is not surprising that even when people with psychiatric conditions are employed their mean wages are significantly lower than those of people without mental illness performing the same jobs (Baldwin \& Marcus, 2006). Public stigma significantly limits employment opportunities, but there are other challenges for people with mental illness.

Public stigma is a deterrent from mental health treatment, but avoidance does not mean symptoms disappear or stop causing limitations or problems. Stigma impedes treatment seeking (Corrigan, 2004), adherence to prescribed treatment (Sirey et al., 2001), and can lead to premature treatment discontinuation (Kreyenbuhl et al., 2011). Stigma also inhibits recovery, and makes it more difficult to overcome mental health-related challenges (Link, Struening, Neese-Todd, Asmussen, \& Phelan, 2001) and can result in psychiatric re-hospitalization (Rüsch et al., 2009c). Mental health professionals themselves are a significant source of public stigma and this is potentially one of the reasons why people with mental illness are deterred from seeking help (Schulze, 2007). Other studies suggest that people with mental illness receive lower quality medical care (Desai, Stefanovics, \& Rosenheck, 2005; Druss, Zhao, von Esenwein, Morrato, \& Marcus, 2011) and that may discourage them from seeking treatment for physical health issues. Combined, health care professionals seem to be expressing attitudes and behaviors that are counter-intuitive to a basic element of their ethical mandate to help people. Yet this likely explains why students in professional programs and health care professionals have been commonly targeted for public anti-stigma interventions (Arboleda-Flórez \& Stuart, 2012; Corrigan, Morris, Michaels, Rafacz, \&Rüsch, 2012). Receiving quality health care from professionals should 
not be contingent on the absence of psychiatric diagnoses or histories.

People with mental illness recognize their conditions are stigmatized and this is not without consequence. Self-stigma as described above is a common experience among people with mental illness (Brohan, Gauci, Sartorius, \& Thornicroft, 2011). A review of the literature suggests that self-stigma diminishes hope, self-esteem, self-efficacy, empowerment, and quality of life for people with mental illness (Livingston \& Boyd, 2010). Self-stigma research has shown it to undermine hope in overcoming psychiatric illnessand that it may be the obverse of personal empowerment (Brohan et al., 2010). Such harmful impacts of selfstigma result from internalizing the prejudicesmay prevent social participation due to a sense of "why try" self-deprecation. Not all people with mental illness experience "why try," but when people with mental illness pursuing of higher education were asked about their willingness to disclose they opted to protect their vulnerable identity to avoid defamation and adverse consequences (Martin, 2010). Despite self-stigma's negative effects, research shows that other reactions are to fight against social inequality (Corrigan \& Watson, 2002). In any case, interventions throughout the world have sought to counteract both public and self-stigma's negative effects.

\section{THREE PUBLIC STIGMA CHANGE STRATEGIES}

Approaches to public stigma change have been divided into three paradigms on the basis of a review of social-psychological research related to racial-ethnic and gender minority groups: education, contact, and protest (Corrigan \& Penn, 1999). Educational approaches to stigma change challenge inaccurate stereotypes about mental illnesses by replacing them with factual information (e.g, contrary to the myth that people with mental illnesses are homicidal maniacs, the differential homicide rate by people with serious psychiatric conditions compared to the general public is minuscule). Educational strategies have used public service announcements, books, flyers, movies, videos, Web pages, podcasts, virtual reality, and other audiovisual aids (cf Corrigan et al., 2012). Some benefits of educational interventions include their low cost and broad reach.

A second stigma change strategy is interpersonal contact with members of the stigmatized group. Here individuals of the general population interact with people with mental illnesses who are likely to lessen their levels of prejudice. Social-psychological research has identified factors that seem to moderate contact effects including one-to-one contact so that people who engage with one another can learn of similar interests and potentially cultivate friendships. A common goal is to expose a person to a moderately disconfirming example to counteract prevailing stereotypes, a more effective method than exposure to extreme examples that shatter stereotypes that a person easily dismisses (Pettigrew \& Tropp, 2006).

The third stigma change method is social activism. Protest is used to highlight various forms of injustices from stigma and reprimand offenders for their stereo- 
types and discrimination: "Shame on us all for perpetuating that people with psychiatric disorders are just 'big kids' who are unable to care for their selves." Anecdotal evidence suggests that protest can reduce harmful media representations (Wahl, 1995).

Research on these three public stigma change strategies has grown exponentially over the past decade as indicated by published systematic reviews (Holzinger, Dietrich, Heitmann, \& Angermeyer, 2008). Recently a meta-analysis evaluated 79 studies of public stigma change strategies specific to mental illness with outcome data on more than 38,000 research participants (Corrigan et al., 2012a). Nearly all studies either used contact or education strategies while protest was notably absent from the research literature. Results showed that both education and contact programs led to significant change in overall outcomes as well as attitudes and behavioral intentions compared to control group assessments. However, contact yielded stronger outcomes by more than twofold over the effect sizes for education. While this result may seem to make the argument for discontinuation of educational strategies, it would be premature to throw out education. Empirical evidence has yet to determine the most cost effective messaging strategy appropriate for specific audiences' needs (McCrone, Knapp, Henri, \& McDaid, 2010). Perhaps there are messages that are best suited for a broad audience (e.g., the general public) such as "recovery is possible" or "see the person not the illness" but more specific groups may need to hear more targeted messages (Clement et al., 2010). For example, a civic club may benefit from only hearing a "recovery is possible" message and increase the audience's general willingness to interact with individuals with a mental illness; but perhaps police officers need to hear more specific information such as how to appropriately intervene during a mental health crisis. Only presenting a general recovery messageto police officerswho do crisis interventionsmay not address that group's specific needs. Therefore, the integration of educational and contact approaches may be most effective for stigma change. For example, the Canadian Mental Health Commission has built much of its Opening Minds program with its contact-education strategy. The most effective message tailoringfor different audiences still remains an empirical question. Current research is underway to understand the aspects that comprise not only effective messages but also the other anti-stigma program ingredients that comprise the most effective contactbasedstrategies (Corrigan et al., 2012b).

\section{SELF-STIGMA CHANGE STRATEGIES}

Over the past decade, research on self-stigma change strategies has been less extensive and trends suggest different perspectives. A recent review yielded fourteen studies that have tested self-stigma change programs (Mittal, Sullivan, Chekuri, Allee, \& Corrigan, 2012). The most common method was psychoeducation-based programs. In these programs participants learn facts that counter stereotypes of illness. These group-based educational strategies use program par- 
ticipants' personal experience with prejudice and discuss the implications of its internalization. In the review, a second self-stigma discussed reduction approach incorporates a more therapeutic strategy, cognitive behavior therapy (CBT). In this intervention, self-stigma was framed as maladaptive statements about the self that individuals were taught to challenge through the solicitation of feedback from others. The goal was to help program attendees develop skills in reframing and correcting their own negative self-directed cognitions. A third self-stigma approach described in the review is a variant of CBT known as Acceptance and Commitment Therapy. This intervention utilized mindfulness strategies to promote self-esteem among group participants. A fourth self-stigma intervention described was a CBT-based program focusing on narrative enhancement. Participants were asked to share personal stories about themselves and their experiences with illness and treatment, while focusing on themes of hope that would counter negative self-stereotypes. Finally, beyond the review is another type of intervention that is yet to be empirically tested which uses a peer-led group process to guide the decisions involved in disclosure of one's mental illness. One such program, Coming Out Proud, may be able to counteract self-stigma's consequences by addressing the costs and benefits of disclosure and how to tell your story about mental illness (Corrigan, Kosyluk,\& Rüsch, in press).

Taken together, data from the four empirically tested interventions suggest that tailoring efforts to challenge self-stigmatizing statements may counteract the negative consequences of self-stigma. While these self-stigma approaches may have long-term merit, there is a risk that they reframe self-stigma as an illness (or personal fault) there by warranting individual psychotherapeutic treatment rather than broader social change. The message that may be unintentionally conveyed is that stigma is aproblem within the person with the mental illness. These rather clinical treatments may help people with mental illness deal with self-stigma in the short term, but we must not ignore stigma's irreducibly social origins.

\section{CONCLUSIONS}

In this review we provided an overview of stigma including its origin, main components - stereotypes, prejudice and discrimination -, and consequences, with a focus on consequences of public and self-stigma for persons with mental illness. We then discussed current public stigma change strategies as well as self-stigma interventions. Current empirical evidence suggests that public stigma delivered through interpersonal contact yields stronger effects than educational strategies. However a hybrid of such methods, contact-educational strategies, may result in even greater impact when an audience receives tailored messages that address more group-specific informational needs. Providing highly relevant content in a presentation can give an audience concrete ideas that encourage real behavioural change. More research is needed regarding the most effective content for tailored presentations.

Public stigma has a major impact on the lives of people with mental illness. 
It leads to self-stigma and may also interfere with various life areas including employment, housing, health care, and quality of life. It thus remains a clinical and social justice priority to provide on-going support for people with mental illness, and continue to develop and evaluate both general and more targeted anti-stigma interventions.

\section{REFERENCES}

Adewuya, A., \& Makanjuola, R. (2005). Social distance towards people with mental illness amongst Nigerian university students. Social Psychiatry and Psychiatric Epidemiology, 40(11), 865-868. doi:10.1007/s00127-005-0965-3.

Anglin, D., Link, B., \& Phelan, J. (2006). Racial differences in stigmatizing attitudes toward people with mental illness. Psychiatric Services, 57(6), 857862. doi:10.1176/appi.ps.57.6.857.

Arboleda-Flórez, J., \& Stuart, H. (2012). From sin to science: Fighting the stigmatization of mental illnesses. The Canadian Journal of Psychiatry / La Revue Canadienne de Psychiatrie, 57(8), 457-463.

Baldwin, M. L., \& Marcus, S. C. (2006). Perceived and measured stigma among workers with serious mental illness. Psychiatric Services, 57(3), 388-392. doi:10.1176/appi.ps.57.3.388

Bambra, C., \& Pope, D. (2007). What are the effects of anti-discriminatory legislation on socioeconomic inequalities in the employment consequences of ill health and disability? Journal of Epidemiology and Community Health,61(5), 421-426. doi:10.1136/jech.2006.052662

Brohan, E., Gauci, D., Sartorius, N., \& Thornicroft, G. (2011). Self-stigma, empowerment and perceived discrimination among people with bipolar disorder or depression in 13 European countries: The GAMIAN-Europe study. Journal of Affective Disorders, 129(1-3), 56-63. doi:10.1016/j.jad.2010.09.001

Brohan, E., Henderson, C., Wheat, K., Malcolm, E., Clement, S., Barley, E. A., \& Thornicroft, G. (2012). Systematic review of beliefs, behaviours and influencing factors associated with disclosure of a mental health problem in the workplace. BMC Psychiatry, 12. doi:10.1186/1471-244X-12-11

Brohan, E., Slade, M., Clement, S.,\& Thornicroft, G. (2010). Experiences of mental illness stigma, prejudice and discrimination: a review of measures. BMC Health Services Research 10(80).

Cechnicki, A., Angermeyer, M. C., \& Bielańska, A. (2011). Anticipated and experienced stigma among people with schizophrenia: Its nature and correlates. Social Psychiatry and Psychiatric Epidemiology, 46(7), 643-650. doi:10.1007/s00127-010-0230-2

Clement, S., Jarrett, M., Henderson, C., \& Thornicroft, G. (2010). Messages to use in population-level campaigns to reduce mental health-related stigma: Consensus development study. Epidemiology and Psychiatric Sciences, 19(1), 72-79.

Corrigan, P. W. (2004). How Stigma Interferes With Mental Health Care. Ameri- 
can Psychologist, 59(7), 614-625. doi:10.1037/0003-066X.59.7.614

Corrigan, P. W., Kosyluk, K. A.,\& Rüsch, N. (in press). Reducing self-stigma by coming out proud. American Journal of Public Health.

Corrigan, P.W., Larson, J.E., Rüsch, N. (2009). Self-stigma and the "why try" effect: impact on life goals and evidence-based practices. World Psychiatry, $8(2), 75-81$.

Corrigan, P. W., Morris, S. B., Michaels, P. J., Rafacz, J. D., \& Rüsch, N. (2012a). Challenging the public stigma of mental illness: A meta-analysis of outcome studies. Psychiatric Services 63(10), 963-973. doi: 10.1176/appi. ps. 201100529

Corrigan, P. W., \& Rao, D. (2012). On the self-stigma of mental illness: Stages, disclosure, and strategies for change. The Canadian Journal of Psychiatry / La Revue Canadienne de Psychiatrie, 57(8), 464-469.

Corrigan, P. W., \& Penn, D. L. (1999). Lessons from social psychology on discrediting psychiatric stigma. American Psychologist, 54(9), 765-776. doi:10.1037/0003-066X.54.9.765

Corrigan, P. W., Tsang, H. H., Shi, K., Lam, C. S., \& Larson, J. (2010). Chinese and American employers' perspectives regarding hiring people with behaviorally driven health conditions: The role of stigma. Social Science \& Medicine, 71(12), 2162-2169. doi:10.1016/j.socscimed.2010.08.025

Corrigan, P.W., Vega, E., Larson, J., Michaels, P. J., McClintock, G., Krzyzanowski, R., Gause, M., \& Buchholz, B. (2012b). The California schedule of key ingredients for contact-based anti-stigma programs. Manuscript submitted for publication.

Corrigan, P. W., \& Watson, A. C. (2002). The paradox of self-stigma and mental illness. Clinical Psychology: Science and Practice, 9(1), doi:10.1093/clipsy/9.1.35

de Toledo Piza Peluso, É., \& Blay, S. (2004). Community perception of mental disorders: A systematic review of Latin American and Caribbean studies. Social Psychiatry and Psychiatric Epidemiology, 39(12), 955-961. doi:10.1007/ s00127-004-0820-y.

Desai, R. A., Stefanovics, E. A., \& Rosenheck, R. A. (2005). The role of psychiatric diagnosis in satisfaction with primary care: Data from the Department of Veterans Affairs. Medical Care, 43(12), 1208-1216. doi:10.1097/01. mlr.0000185747.79104.90

Druss, B. G., Zhao, L., von Esenwein, S., Morrato, E. H., \& Marcus, S. C. (2011). Understanding excess mortality in persons with mental illness: 17year follow up of a nationally representative US survey. Medical Care, 49(6), 599-604.

Goffman, E. (1963). Stigma: notes on the management of spoiled identity. Englewood Cliffs, NJ: Prentice Hall.

Jones, C.P. (1987). Stigma: Tattooing and branding in Graeco-Roman antiquity. Journal of Roman Studies, 77, 139-155.

Jorm, A., \& Wright, A. (2008). Influences on young people's stigmatising atti- 
tudes towards peers with mental disorders: National survey of young Australians and their parents. British Journal of Psychiatry, 192(2), 144-149. doi:10.1192/bjp.bp.107.039404.

Kreyenbuhl, J., Slade, E. P., Medoff, D. R., Brown, C. H., Ehrenreich, B., Afful, J., \& Dixon, L. B. (2011). Time to discontinuation of first- and second-generation antipsychotic medications in the treatment of schizophrenia. Schizophrenia Research, 131(1-3), 127-132. doi:10.1016/j.schres.2011.04.028

Holzinger A, Dietrich S, Heitmann S, Angermeyer M. Evaluation zielgruppenorientierter Interventionen zur Reduzierung des Stigmas psychischer Krankheit: Eine systematische Übersicht. Psychiatrische Praxis 35:376-386, 2008

Lauber, C., \& Rössler, W. (2007). Stigma towards people with mental illness in developing countries in Asia. International Review of Psychiatry, 19(2), 157178. doi:10.1080/09540260701278903.

Link, B. G., \& Phelan, J. C. (2001). Conceptualizing stigma. Annual Review of Sociology, 27, 363-385. doi:10.1146/annurev.soc.27.1.363

Link, B. G., Struening, E. L., Neese-Todd, S., Asmussen, S., \& Phelan, J. C. (2001). Stigma as a barrier to recovery: The consequences of stigma for the self-esteem of people with mental illnesses. Psychiatric Services, 52(12), 1621-1626. doi:10.1176/appi.ps.52.12.1621

Livingston, J. D., \& Boyd, J. E. (2010). Correlates and consequences of internalized stigma for people living with mental illness: A systematic review and meta-analysis. Social Science \& Medicine, 71(12), 2150-2161. doi:10.1016/j. socscimed.2010.09.030

Martin, J. (2010). Stigma and student mental health in higher education. Higher Education Research \& Development, 29(3), 259-274. doi:10.1080/07294360903470969

Marx, G.T. (2001). Technology and social control: The search for the illusive silver bullet. In P.B. Baltes \& N.J. Smelser (Eds.), International encyclopedia of the social and behavioral sciences (Volume 23, pp. 15506-15512). Amsterdam/New York: Elsevier.

McCrone, P., Knapp, M., Henri, M., \& McDaid, D. (2010). The economic impact of initiatives to reduce stigma: Demonstration of a modelling approach. Epidemiology and Psychiatric Sciences, 19(2), 131-139.

Mehta, N., Kassam, A., Leese, M., Butler, G., \& Thornicroft, G.(2009). Public attitudes towards people with mental illness in England and Scotland, 19942003. British Journal of Psychiatry, 194, 278-284.

Mittal, D., Sullivan, G., Chekuri, L., Allee, M. E., \& Corrigan, P. (2012). Empirical self-stigma reduction strategies: A critical review of literature. Psychiatric Services, 63(10),974-981. doi: 10.1176/appi.ps.201100459

Pescosolido, B. A., Martin, J. K., Long, J., Medina, T. R., Phelan, J. C., \& Link, B. G. (2010). "A disease like any other"? A decade of change in public reactions to schizophrenia, depression, and alcohol dependence. The American Journal of Psychiatry, 167(11), 1321-1330. doi:10.1176/appi.ajp.2010.09121743 
Pettigrew, T.,\& Tropp, L. (2006).A meta-analytic test of intergroup contact theory. Journal of Personality \& Social Psychology, 90(5), 751-783.

Rüsch, N., Corrigan, P. W., Wassel, A., Michaels, P., Larson, J. E., Olschewski, M., ... Batia, K. (2009a). Self-stigma, group identification, perceived legitimacy of discrimination and mental health service use. The British Journal of Psychiatry, 195(6), 551-552. doi:10.1192/bjp.bp.109.067157

Rüsch, N., Corrigan, P. W., Powell, K., Rajah, A., Olschewski, M., Wilkniss, S.,\& Batia, K. (2009b). A stress-coping model of mental illness stigma: II. Emotional stress responses, coping behavior and outcome. Schizophrenia Research, 110, 65-71.

Rüsch, N., Corrigan, P. W., Wassel, A., Michaels, P., Olschewski, M., Wilkniss, S., \& Batia, K. (2009c). A stress-coping model of mental illness stigma: I. Predictors of cognitive stress appraisal. Schizophrenia Research, 110(1-3), 59-64. doi:10.1016/j.schres.2009.01.006

Scheid, T. L. (2005). Stigma as a barrier to employment: Mental disability and the Americans with disabilities act. International Journal of Law and Psychiatry, 28(6), 670-690. doi:10.1016/j.ijlp.2005.04.003

Schomerus, G., Matschinger, H., \& Angermeyer, M. C. (2009). The stigma of psychiatric treatment and help-seeking intentions for depression. European Archives of Psychiatry and Clinical Neuroscience, 259(5), 298-306. doi:10.1007/s00406-009-0870-y

Schomerus, G., Matschinger, H., Kenzin, D., Breier, P., \& Angermeyer, M. (2006). Public attitudes towards mental patients: A comparison between Novosibirsk, Bratislava and German cities. European Psychiatry, 21(7), 436441. doi:10.1016/j.eurpsy.2006.01.009.

Schulze, B. (2007). Stigma and mental health professionals: A review of the evidence on an intricate relationship. International Review of Psychiatry, 19(2), 137-155. doi:10.1080/09540260701278929

Sharac, J., McCrone, P., Clement, S., \& Thornicroft, G. (2010). The economic impact of mental health stigma and discrimination: A systematic review. Epidemiology and Psychiatric Sciences, 19(3), 223-232.

Sirey, J., Bruce, M. L., Alexopoulos, G. S., Perlick, D. A., Friedman, S. J., \& Meyers, B. S. (2001). Stigma as a barrier to recovery: Perceived stigma and patient-rated severity of illness as predictors of antidepressant drug adherence. Psychiatric Services, 52(12), 1615-1620. doi:10.1176/appi.ps.52.12.1615

Wahl, O. (1995). Media madness: Public images of mental illness. Piscataway, NJ: Rutgers University Press.

Wahl, O. (1999). Mental health consumers' experience of stigma. Schizophrenia Bulletin, 25(3), 467-478 